\title{
Barreiras que Impedem a Opção das Meninas pelas Ciências Exatas e Computação: Percepção de Alunas do Ensino Médio
}

\author{
Josilene Aires ${ }^{1}$, Giorgia Mattos ${ }^{1}$, Chaenne Oliveira ${ }^{2}$, Andréa Brito ${ }^{2}$, Ana \\ Flávia Aragão ${ }^{2}$, Sanny Alves ${ }^{2}$, Thiago Coelho ${ }^{2}$, Gabriel Moreira ${ }^{2}$
}
${ }^{1}$ Docentes e ${ }^{2}$ Discentes do Centro de Informática - Universidade Federal da Paraíba (UFPB)
Av. Dos Escoteiros, s/n - Mangabeira - 58.055-000 - João Pessoa - PB - Brazil
\{josilene, giorgia\}@ci.ufpb.br\}

\begin{abstract}
In this study, we investigated the reasons that make it difficult for women to choose courses and careers in the area of Science, Technology and Computing. Based on the testimonies of high school students from the State of Paraiba collected in 2016 and 2017, we find that the main perceived barriers are: sexism, the idea that women are 'incapable' of dealing with technology, the fact of the technological area being predominantly masculine and the prejudgment that Computing is 'a man thing', among others. The intervention project conducted by the authors seeks to change this reality through lectures, debates, training workshops and technical visits, influencing the professional choices and the future of the students.
\end{abstract}

Resumo. Neste estudo pesquisamos as razões que dificultam a escolha de cursos e carreiras da área de Ciência, Tecnologia e Computação pelas mulheres. A partir de depoimentos de alunas do ensino médio do Estado da Paraíba coletados em 2016 e 2017, verificamos que as principais barreiras percebidas são: o machismo, a ideia de que as mulheres são 'incapazes' de lidar com tecnologia, o fato da área tecnológica ser predominantemente masculina e o preconceito que Computação é 'coisa de homem', entre outras. $O$ projeto de intervenção conduzido pelas autoras procura mudar esta realidade através da ministração de palestras, oficinas de capacitação e visitas técnicas, influenciando as escolhas profissionais e o futuro das alunas.

\section{Introdução}

A questão sobre porque existem tão poucas mulheres na área de Ciência, Tecnologia e Computação continua a ser feita por educadores, estudiosos e feministas de vários países do mundo globalizado. Os fatores são diversos, e envolvem desde crenças sexistas que as mulheres não possuem competências espaciais e matemáticas (Hill, Corbett, St. Rose, 2010), passando pelo clima hostil do ambiente acadêmico (Cooper \& Eddy et al, 2010) e chegando aos estereótipos de gênero negativos que reduzem a sua autoestima, autoconfiança e autoeficácia.

Baseado nestes estudos teóricos e na reduzida presença de mulheres nos cursos de uma Universidade Federal do Nordeste, decidimos procurar as razões diretamente na fonte, através de pesquisa realizada diretamente com alunas do Ensino Médio de Escolas 
Estaduais da Paraíba. Este estudo apresenta o resultado dos dados coletados através de questionários aplicados em escolas deste Estado em 2016 e 2017, respondidos por alunas do $1^{\circ}$ e $2^{\circ}$ anos do Ensino Médio.

\section{Metodologia}

Esta pesquisa classifica-se como pesquisa-ação exploratória, a qual pode ser compreendida como uma ação que visa mudanças na realidade concreta com uma participação social efetiva. Seus resultados estão vinculados à tomada de consciência dos fatores envolvidos nas situações de vida imediata e na participação coletiva para a mudança da ordem social (Barbier, 1985). O percurso metodológico envolveu os seguintes passos: (i) Pesquisa bibliográfica em periódicos e conferências nacionais e internacionais sobre equidade de gênero na Ciência e Tecnologia e sobre barreiras para a inserção feminina na Computação. (ii) Palestras e debates sobre as escolhas profissionais realizadas com as alunas de ensino médio de escolas do nosso estado. (iii) Aplicação de questionários para conhecimento das barreiras sofridas pelas alunas com relação às escolhas profissionais. (iv) Análise dos resultados através de análise do discurso. Duzentos e cinquenta e quatro alunas (254) do $1^{\circ}$ e $2^{\circ}$ anos de duas Escolas Estaduais de Ensino Médio participaram da pesquisa. $\mathrm{O}$ instrumento de pesquisa utilizado foi um questionário estruturado, com questões objetivas e subjetivas. A Tabela 1 mostra a quantidade de respondentes por escola e ano.

Tabela 1 - Quantidade de participantes. Fonte: Dados da pesquisa, 2017.

\begin{tabular}{|l|l|r|}
\hline Escola & Ano & Quantidade \\
\hline Escola Estadual Rebeca Simões & 2016 & 185 \\
\hline \multirow{2}{*}{ Escola Técnica Estadual } & 2016 & 30 \\
\cline { 2 - 3 } & 2017 & 39 \\
\hline Total & & 254 \\
\hline
\end{tabular}

\section{Barreiras, Preconceitos e Outras Dificuldades}

A questão primordial que investigamos neste estudo é "Existe algum preconceito ou barreira que impeça ou dificulte o ingresso de mulheres na área de Computação". Entre as 254 alunas que responderam o questionário, 106 acham que não; 113 responderam que nunca pensaram sobre isso; e 35 responderam que sim, existe barreira/preconceito. Para estas, foi questionado qual a forma de barreira/preconceito, sendo a resposta aberta e livre. Quando compiladas, foram encontradas as seguintes categorias (Figura 1).

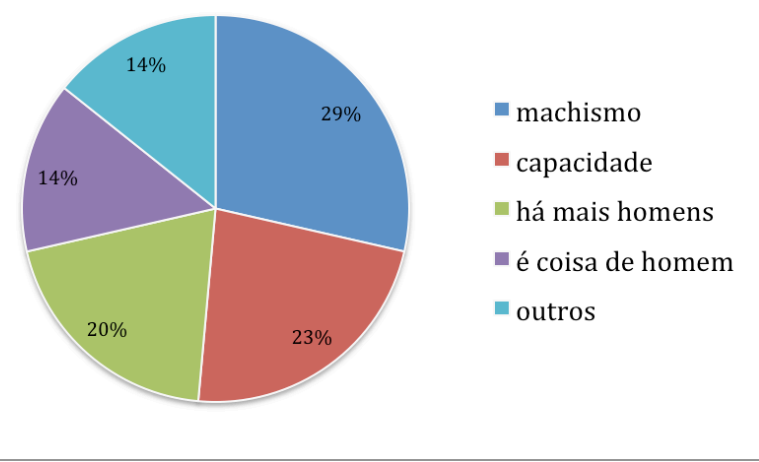

Figura 1 - Percepção das alunas sobre preconceito 


\subsection{Machismo}

A maioria das alunas (29\%) acha que o preconceito está relacionado ao machismo dos homens e da sociedade. Entre as respostas que enumeram "machismo" encontramos:

(A1) Machismo (oito alunas).

(A2) Por ser mulher, visto que o machismo enraizado discrimina as mulheres em diversas áreas.

(A3) Pelo machismo e pela sociedade, que tem dificuldade em ver uma mulher em área masculina.

De fato, os estudos de Amaral et al. (2017) e Oliveira e Prates (2014) relatam as discriminações sofridas por estudantes de computação, com origem no machismo. Alunas do curso de Bacharelado em Sistemas de Informação relatam ter enfrentado situações de discriminação de gênero por parte do corpo docente e de profissionais que trabalham com recrutamento.

\subsection{Falta de Capacidade}

Grande parte das alunas (23\%) acredita que o preconceito está ligado a questões de capacidade da mulher. Ressaltamos algumas das respostas.

(B1) Por ser mulher, visto que o machismo enraizado discrimina as mulheres em

diversas áreas.

(B2) Acharem que nós não temos capacidade para tal área.

(B3) Por pensarem que elas não tem tanta capacidade.

(B4) Porque as pessoas diminuem as mulheres, acham incapazes.

(B5) Que só homens seriam capacitados.

(B6) Acho que a mulher não vai saber tanto quanto o homem.

Não há dúvidas de que a mulher é tão capaz quanto o homem de desempenhar adequadamente os papéis exigidos pelas carreiras de tecnologia. No entanto, a pesquisa realizada em (SIGILO) mostra que uma grande parcela dos meninos que ingressam em Computação já tem noções básicas ou experiência anterior de programação, enquanto que as meninas raramente a possuem. Adicionalmente, os meninos são educados desde criança a utilizarem brinquedos que desenvolvem habilidades mais voltadas à tecnologia, o que os torna mais seguros futuramente.

No entanto, a resposta que mais nos chamou atenção está em B6. Uma das alunas relata o que pensa: ela considera que a mulher não vai saber tanto quanto o homem. Esta percepção está relacionada ao conceito de autoeficácia, no qual as próprias meninas se consideram menos capazes que os meninos.

\subsection{Há Mais Homens Nesta Área}

Várias alunas responderam que consideram uma importante barreira o fato dos homens serem maioria nesta área e profissão (20\%). Vejamos algumas das respostas coletadas.

(C1) É um curso onde há mais homens, então há sim alguma discriminação.

(C2) Homens trabalharem mais nessa área.

(C3) Por ser muitas vezes um trabalho para homens.

(C4) Porque é uma area com mais homens

(C5) Por só ter ela de mulher. 


\subsection{Computação é Coisa de Homem}

Neste caso, as barreiras estão no que a sociedade pensa sobre esta profissão/área. Em geral as alunas referem que a própria sociedade considera a Computação como uma área masculina (respostas D1 a D4). Este conceito está tão arraigado que até mesmo uma das alunas declara que "Isso é coisa só do homem" (D5).

(D1) Por acharem que computação é só para homem.

(D2) Por ser conhecida como área masculina ocorre preconceito.

(D3) As pessoas acharem que isso é só para homem.

(D4) A sociedade mostra que é trabalho para homem.

(D5) Isso é coisa só do homem.

Em geral os homens acreditam que as mulheres não possuem as habilidades necessárias para a computação e a tecnologia. Estas relações de poder que 'determinam' que apenas os homens dominam os artefatos tecnológicos foram conceituadas por Pierre Bourdieu (1999) como parte da dominação masculina.

\subsection{Outras Percepções}

Finalmente, apresentamos um conjunto de respostas que mostram outras percepções sobre as barreiras e preconceito que dificultam o ingresso de mulheres na área e nos cursos de Computação.

(E1) A mulher pode ser taxada como 'homem' por fazer um curso no qual a presença deles é maior.

(E2) Sofre preconceito e recebe menos que o homem.

(E3) Pois vivemos em uma sociedade que ainda tem que melhorar.

(E4) Sofrem preconceito dos homens.

(E5) Mulher foi feita para cuidar da casa.

Na percepção de uma das alunas, a mulher pode ser considerada masculina por estar em um meio onde os homens predominam. Realmente, existem estudos que comprovam que algumas das mulheres tendem a se vestir e se comportar de modo a esconder seus atributos femininos físicos, a fim de serem aceitas pela comunidade de homens.

\section{Comentários Finais}

Neste trabalho apresentamos a percepção de alunas do Ensino Médio de algumas escolas do Estado da Paraíba quanto às barreiras e preconceitos que dificultam a sua entrada e permanência na área da Ciência da Computação. Mesmo que o número de alunas respondentes seja reduzido, através dessa amostragem percebe-se que as meninas enfrentam inúmeras dificuldades que as impedem até mesmo de pensar em ingressar nesta área.

O projeto Meninas na Computação, coordenado pelas docentes autoras, trabalha na vertente de mudança do paradigma de "Falta de capacidade feminina na área". Através de oficinas de capacitação em diversas subáreas da Computação, procuramos promover o empoderamento feminino através do conhecimento. Dessa forma, acreditamos que capacitar as meninas é uma forma de promover a equidade de gênero, ampliando suas possibilidades de escolhas profissionais e de progresso econômico e social. 


\section{Referências}

Amaral, M. A., Emer, M. C. F. P., Bim, S. A. S, Gomes, M., Gonçalves, M. M. (2017). Investigando questões de gênero em um curso da área de Computação. Revista Estudos Feministas, 25(2). https://dx.doi.org/10.1590/1806-9584.2017v25n2p857.

Barbier, R. (1985) A Pesquisa-Ação na Instituição Educativa. Rio de Janeiro: Zahar.

Bourdieu, Pierre (1999). A dominação masculina. Ed. 2. Rio de Janeiro: Bertrand Brasil.

Cooper, J., Eddy, P., Hart, J., Lester, J., Lukas, S., Eudey, B., Glazer-Raymo, J., Madden, M. (2010). Improving gender equity in postsecondary education. Handbook for Achieving Gender Equity through Education (2 ed., pp. 631-653). New York and London: Routledge.

Hill, C., Corbett, C. e St. Rose, A. (2010). Why so few? Women in Science, Technology, Engineering, and Mathematics. AAUW, Washington DC.

Oliveira, A. C., Moro, M. M., \& Prates, R. O. (2014). Perfil feminino em computação: Análise inicial. In XXXIV Congresso da Sociedade Brasileira da Computação. 